\title{
Facile synthesis of novel flowerlike magnetic mesoporous carbon for efficient chlorophenols removal
}

\author{
Shuangliu Liu ${ }^{\mathrm{a}, \mathrm{b}, \mathrm{c}}$, Sheng $\mathrm{Li}^{\mathrm{d}, 1}$, Hongyun Niu ${ }^{\mathrm{b}, *}$, Tao Zeng ${ }^{\mathrm{b}}$, Yaqi Cai ${ }^{\mathrm{b}}$, Chunhong Shi ${ }^{\mathrm{a}, *}$, Beihai Zhou ${ }^{\mathrm{a}}$, \\ Fengchang $\mathrm{Wu}^{\mathrm{c}}$, Xiaoli Zhao ${ }^{\mathrm{c}}$ \\ a Department of Environmental Engineering, University of Science and Technology Beijing, Beijing 100083, China \\ ${ }^{\mathrm{b}}$ State Key Laboratory of Environmental Chemistry and Ecotoxicology of Research Center for Eco-Environmental Sciences, Chinese Academy of Sciences, Beijing 100085, China \\ 'State Key Laboratory of Environmental Criteria and Risk Assessment, Chinese Research Academy of Environmental Sciences, Beijing 100012, China \\ ${ }^{\mathrm{d}}$ The Geriatric Department of Cardiology, PLA General Hospital, Beijing 100853, China
}

\section{A R T I C L E I N F O}

\section{Article history:}

Received 27 February 2014

Received in revised form 12 August 2014

Accepted 22 August 2014

Available online 2 September 2014

\section{Keywords:}

Magnetic

Mesoporous carbon

Layered double hydroxide

Dopamine

Chlorophenol

\begin{abstract}
A B S T R A C T
We present here a novel, low cost and environmental-friendly synthetic strategy for fabricating flowerlike magnetic mesoporous carbon (MMC) microspheres by using silica coated $\mathrm{Fe}_{3} \mathrm{O}_{4}$ as core, anisotropic layered double hydroxide (LDH) nanocrystals as hard template and dopamine as carbon source, respectively. The resulting MMC spheres has high surface areas $\left(90.3 \mathrm{~m}^{2} \mathrm{~g}^{-1}\right)$, excellent magnetic response (16.99 emu g $\left.{ }^{-1}\right)$, and large mesopore volume $\left(0.22 \mathrm{~cm}^{3} \mathrm{~g}^{-1}\right)$, as well as good chemical inertness and mechanical stability. The MMC spheres were used to adsorb 2,4,6-trichlorophenol (TCP) from simulated water samples. Experiment results suggest that the adsorption was favorable at acidic $\mathrm{pH}$ and increased with the rise of initial TCP concentration and temperature. Kinetic parameters were proved to follow the pseudo-second-order kinetics model and the equilibrium data was more favorable for Freundlich isotherm. The equilibrium absorption capacity was $210 \mathrm{mg} \mathrm{g}^{-1}$ at initial TCP concentration of $20 \mathrm{mg} \mathrm{L}^{-1}$ and increased to $587 \mathrm{mg} \mathrm{g}^{-1}$ when the initial TCP concentration was up to $100 \mathrm{mg} \mathrm{L}^{-1}$, which was much higher than those of other carbon-based adsorbents reported in literature. To the best of our knowledge, this is the first report on the synthesis of flowerlike MMC material by using LDH as template and its application as adsorbent to remove TCP.
\end{abstract}

(c) 2014 Elsevier Inc. All rights reserved.

\section{Introduction}

In recent years, mesoporous carbon (MC) materials with excellent textural characteristics, high specific surface area, and good chemical and thermal stability have gained increasing attention [1-4]. Their unique channel network provides a highly opened porous host with easy and direct access for guest species. Despite considerable progress in the synthesis of MC, there is a big issue in the separation of $\mathrm{MC}$ from aqueous solution. Conventional solid-liquid methods, including filtration and centrifugation, are time consuming and inefficient. Therefore, magnetically functionalized carbon materials have entered into our sight [5].

So far, magnetic mesoporous carbon (MMC) materials have been synthesized by various methods, such as polymerization, hard template approach, and sol-gel process [6-8]. Among these,

\footnotetext{
* Corresponding authors. Tel.: +86 010 62849182; fax: +86 01062849239 .

E-mail addresses: hyniu@rcees.ac.cn (H. Niu), sch.22@163.com (C. Shi).

1 The author contributed equally to this work.
}

templating is the method widely used to design and fabricate porous carbon materials [9-11]. It involves infiltration of the pores of the template with appropriate carbon precursor, carbonization, and subsequent template removal. Great progress in fabrication of MMC has been made by developing various templates, such as zeolites and silica $[11,2,12]$. But it usually takes a long time to synthesize and requires strong corrosive acid or concentrated alkali to dissolve these templates. Moreover, the pore size of these templates is generally less than $2.5 \mathrm{~nm}[13,14]$, which provides a considerable diffusion barrier for carbon precursor molecules' spread. Layered double hydroxide (LDH) with large surface area, low cost, three-dimensional structure has been demonstrated huge potential for drug delivery, catalysis, sensing, and pollutants adsorption [15-19]. The orientation and dimensionality hierarchical structure as well as the large expandable interlayer free space make it easier for further modification. Specially, previous researches have reported that the LDH template could be synthesized in a short time [19] and be dissolved under mild acid pH [20], which enable it to be an ideal template candidate. Up to now, the synthesis of MMC by using $\mathrm{LDH}$ as template has not been reported yet. 


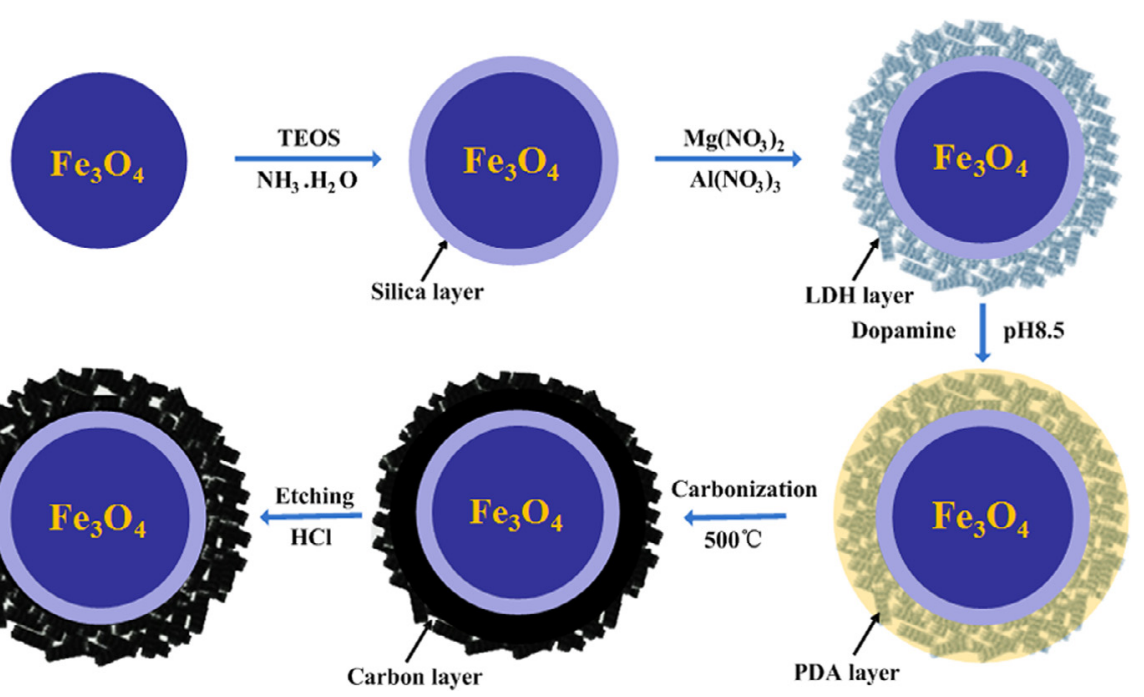

Scheme 1. Synthesis of $\mathrm{Fe}_{3} \mathrm{O}_{4} @ \mathrm{SiO}_{2} @$ meso C (MMC) microsphere.

Glucose [21], pyrroles [22] and phenolic resins [23] are often served as carbon precursor. The hydrolysis process of these carbon precursors generally suffers from either a relatively high temperature or a water bath heating. In addition, some of precursors, such as formaldehyde and resorcinol, are harmful to people [24,25]. Dopamine, a biomolecule which contains numerous amine and catechol functional groups, has the ability of adhering to almost all material surfaces and autopolymerization to form polydopamine (PDA) coating under alkaline condition at room temperature [26]. The formation of PDA coating is simple, inexpensive and high yield and the thickness of PDA coating can be readily controlled by changing the experimental parameters. Although dopamine has been previously utilized for the surface modification of various nanoparticles [27-29], there is only limited research on preparing $\mathrm{Fe}_{3} \mathrm{O}_{4}$-based porous carbon materials by using a dopamine polymer as the carbon precursor.

Herein, we report a novel and gentle approach to synthesize flowerlike MMC microspheres by using silica coated magnetite $\mathrm{Fe}_{3} \mathrm{O}_{4}$ as core, porous $\mathrm{Mg}-\mathrm{Al} \mathrm{LDH}$ as template and dopamine as carbon precursor. Scheme 1 illustrates the synthesis of MMC materials. First, uniform magnetite nanoparticles were coated with a thin silica layer by sol-gel approach to obtain $\mathrm{Fe}_{3} \mathrm{O}_{4} @ \mathrm{SiO}_{2}$ composites. Then, $\mathrm{Mg}-\mathrm{Al} \mathrm{LDH}$ nanoflakes were perpendicularly deposited on the $\mathrm{Fe}_{3} \mathrm{O}_{4} @ \mathrm{SiO}_{2}$ microspheres $\left(\mathrm{Fe}_{3} \mathrm{O}_{4} @ \mathrm{SiO}_{2} @ \mathrm{LDH}\right)$. Third, the free space of $\mathrm{LDH}$ was charged of PDA $\left(\mathrm{Fe}_{3} \mathrm{O}_{4} @ \mathrm{SiO}_{2} @ \mathrm{LDH} @ P D A\right)$ and carbonized at $500{ }^{\circ} \mathrm{C}$. Finally, LDH templates were removed by treating with $\mathrm{HCl}$ to form a mesoporous carbon shell, resulting in well-dispersed $\mathrm{Fe}_{3} \mathrm{O}_{4} @ \mathrm{SiO}_{2} @$ meso C (MMC). Compared with other methods of $\mathrm{Fe}_{3} \mathrm{O}_{4}$-based mesoporous carbon formation, additional toxic reagent and water bath are not needed. At the same time, the hierarchical porous structures of LDH template are beneficial for carbon precursor to transport and diffuse. The MMC were applied as adsorbent for the removal of 2,4,6-trichlorophenol (TCP) which has been regarded to be carcinogenic, teratogenic and mutagenic [30]. To the best of our knowledge, there has been no report on MMC prepared by $\mathrm{LDH}$ template with the oxidative self-polymerization of dopamine and used in the adsorption of TCP.

\section{Experimental section}

\subsection{Chemicals and materials}

All reagents were of analytical reagent grade and used without further purification. Ferric chloride hexahydrate $\left(\mathrm{FeCl}_{3} \cdot 6 \mathrm{H}_{2} \mathrm{O}\right)$, ethylene glycol (EG), magnesium nitrate hexahydrate $\left(\mathrm{Mg}\left(\mathrm{NO}_{3}\right)_{2}\right.$. $\left.6 \mathrm{H}_{2} \mathrm{O}\right)$, aluminum nitrate nonahydrate $\left(\mathrm{Al}\left(\mathrm{NO}_{3}\right)_{3} \cdot 9 \mathrm{H}_{2} \mathrm{O}\right)$, sodium acetate $(\mathrm{NaAc})$, ammonia $\left(\mathrm{NH}_{3} \cdot \mathrm{H}_{2} \mathrm{O}\right)$, trisodiumcitrate dehydrate, 2-amino-2-hydroxymethylpropane-1,3-diol (Tris), hydrochloric acid $(\mathrm{HCl})$, tetraethyl orthosilicate $(\mathrm{Si}(\mathrm{OC} 2 \mathrm{H} 5) 4)$, and ethanol ( $\mathrm{C} 2 \mathrm{H} 5 \mathrm{OH})$ were purchased from Sinopharm Chemistry Reagent Co., Ltd. (Beijing, China). 3-Hydroxytyramine hydrochloride (dopamine), and 2,4,6-trichlorophenol were obtained from J\&K Chemical Ltd. (Beijing, China). A stock solution of TCP (200 mg L $\left.{ }^{-1}\right)$ was prepared and further diluted to the desired concentrations before use. Ultrapure water used in all of the experiments was prepared by using Milli-Q SP reagent water system (Millipore, Bedford, MA, USA).

\subsubsection{Synthesis of $\mathrm{Fe}_{3} \mathrm{O}_{4} @ \mathrm{SiO}_{2}$ nanoparticles}

The $\mathrm{Fe}_{3} \mathrm{O}_{4}$ particles were prepared via a solvothermal method as described previously [29]. Then the $\mathrm{Fe}_{3} \mathrm{O}_{4} @ \mathrm{SiO}_{2}$ microspheres were prepared through a versatile sol-gel method [14]. In brief, magnetite $\mathrm{Fe}_{3} \mathrm{O}_{4}(0.85 \mathrm{~g})$ was dispersed in a round-bottom flask charged with ethanol $(200 \mathrm{~mL})$, water $(50 \mathrm{~mL})$ and concentrated ammonia solution $(3.60 \mathrm{~mL}, 28 \mathrm{wt} \%)$. The suspension was ultrasonicated for $30 \mathrm{~min}$ (ultrasonic cleaner, KQ-500DE, $500 \mathrm{~W}, 40 \mathrm{kHz}$ ). After that $2.5 \mathrm{~mL}$ of tetraethyl orthosilicate (TEOS) was added dropwise followed by continuous mechanical stirring for $8 \mathrm{~h}$. The resultant $\mathrm{Fe}_{3} \mathrm{O}_{4} @ \mathrm{SiO}_{2}$ microsphere was collected from the reaction mixture under an external magnetic field, washed with ethanol several times, and dried at $50{ }^{\circ} \mathrm{C}$ under vacuum.

\subsubsection{Synthesis of $\mathrm{Fe}_{3} \mathrm{O}_{4} @ \mathrm{SiO}_{2} @ M g-A l L D H$ microspheres}

$0.1 \mathrm{~g} \mathrm{Fe}_{3} \mathrm{O}_{4} @ \mathrm{SiO}_{2}$ spheres were dispersed in $50 \mathrm{~mL}$ of deionized (DI) water $(\mathrm{pH}=10)$. Then $20 \mathrm{~mL}$ of aqueous solution containing $1.44 \mathrm{mmol}$ of $\mathrm{Mg}\left(\mathrm{NO}_{3}\right)_{2} \cdot 6 \mathrm{H}_{2} \mathrm{O}$ and $0.48 \mathrm{mmol}$ of $\mathrm{Al}\left(\mathrm{NO}_{3}\right)_{3} \cdot 9 \mathrm{H}_{2} \mathrm{O}$ was dropped into the above suspension under vigorous stirring and the solution $\mathrm{pH}$ maintained at $\mathrm{pH} 10$. After that, the mixture was under ultrasonication for $1 \mathrm{~h}$ (ultrasonic cleaner, KQ-500DE, $500 \mathrm{~W}, 40 \mathrm{kHz}$ ). The obtained $\mathrm{Fe}_{3} \mathrm{O}_{4} @ \mathrm{SiO}_{2} @ \mathrm{Mg}-\mathrm{Al} \mathrm{LDH}$ microspheres were washed with DI water several times, and dried at $50{ }^{\circ} \mathrm{C}$ under vacuum.

\subsubsection{Synthesis of $\mathrm{Fe}_{3} \mathrm{O}_{4} @ \mathrm{SiO}_{2} @$ meso $\mathrm{C}$ composites}

$0.2 \mathrm{~g}$ of the obtained $\mathrm{Fe}_{3} \mathrm{O}_{4} @ \mathrm{SiO}_{2} @ \mathrm{Mg}-\mathrm{Al} \mathrm{LDH}$ microspheres and $0.2 \mathrm{~g}$ of dopamine were dispersed in $100 \mathrm{~mL}$ of $\mathrm{HCl}-$ Tris solution ( $\mathrm{pH} 8.5,10 \mathrm{mM}$ Tris), followed by vigorous stirring for $12 \mathrm{~h}$. The precipitated black solid product $\left(\mathrm{Fe}_{3} \mathrm{O}_{4} @ \mathrm{SiO}_{2} @ \mathrm{LDH} @ P D A\right)$ was 
washed with DI water several times, and dried at $50{ }^{\circ} \mathrm{C}$ under vacuum. Then the product was calcined in a tube furnace under the protection of nitrogen at $500{ }^{\circ} \mathrm{C}$ for $4 \mathrm{~h}$. Finally, the carbonized material was soaked in $0.5 \mathrm{M} \mathrm{HCl}$ solution for $8 \mathrm{~h}$ to dissolve the LDH framework followed by washing with DI water and drying at $50{ }^{\circ} \mathrm{C}$ under vacuum.

\subsection{Characterization}

The size and morphology of all materials were investigated by using a transmission electron microscope (TEM) of H-7500 (Hitachi, Japan) and a Hitachi S-2400 scanning electron microscope equipped with an energy dispersive X-ray spectrometer (SEMEDX, Tokyo, Japan). The crystal phase was collected by a PAN analytical X'pert Pro diffractometer (XRD, Almelo, Netherlands) by using a $\mathrm{Cu}$ $\mathrm{K} \alpha$ radiation ranging from $10^{\circ}$ to $80^{\circ}$ with a scan step of $0.02^{\circ}$. The specific surface area, pore size and volume analysis were carried out by BET methods (ASAP2000 V3.01A; Micromeritics, Norcross, GA). FTIR spectra were recorded on a NEXUS 670 Infrared Fourier Transform Spectrometer (Nicolet Thermo, Waltham, MA). The magnetization curves were acquired by a vibrating sample magnetometer (VSM, LDJ9600, Troy, MI). X-Ray photoelectron spectroscopy (XPS) was measured with an ESCA-Lab-200i-XL spectrometer (Thermo Scientific, Waltham, MA) with monochromatic $\mathrm{Al} \mathrm{K} \alpha$ radiation $(1486.6 \mathrm{eV})$.

\subsection{Batch adsorption experiments}

Batch experiments were performed to examine the adsorption behavior of TCP on MMC. Adsorption of TCP as a function of $\mathrm{pH}$ onto MMC was first examined in a series of experiments where the initial TCP concentration was maintained constant $\left(20 \mathrm{mg} \mathrm{L}^{-1}\right)$ at varying $\mathrm{pH}$ values $(\mathrm{pH} 2-11)$ and then the optimum $\mathrm{pH}$ for adsorption was determined. Adsorption isotherm studies were conducted at 303, 313 and $323 \mathrm{~K}$ with initial TCP concentrations ranging in $1-20 \mathrm{mg} \mathrm{L}^{-1}$ at optimal $\mathrm{pH}$ in DI water. Solution $\mathrm{pH}$ was adjusted with $0.5 \mathrm{M} \mathrm{NaOH}$ or $\mathrm{HCl}$. Different amount of $\mathrm{NaCl}$ and humic acid (HA) were introduced to investigate the influence of ionic strength and natural organic matter, respectively. Kinetic studies were performed with the initial TCP concentration of $20 \mathrm{mg} \mathrm{L}^{-1}$ and certain reaction mixture was drawn out and analyzed for residual TCP at set intervals. All batch tests were executed in $15 \mathrm{~mL}$ of polyethylene bottles by taking $0.2 \mathrm{mg}$ (dry weight) of MMC with $10 \mathrm{~mL}$ of TCP solution. Reactions proceeded in a temperature-controlled shaker at $200 \mathrm{rpm}$ for $10 \mathrm{~h}$. After equilibrium, the solid and solution were separated with an $\mathrm{Nd}-\mathrm{Fe}-\mathrm{B}$ strong magnet. Adsorption parallel experiments were carried out in triplicate and averaged results were used.

\subsection{HPLC analysis}

The detection of TCP was quantified by using a HPLC system (DIONEX, USA). The HPLC equipment include a DIONEX P680 HPLC pump, a thermostatted column compartment TCC-100 and a PDA100 photodiode array detector. Separations were conducted on a Dikma $\mathrm{C}_{18}$ column $(250 \times 4.6 \mathrm{~mm} ; 5 \mu \mathrm{m})$. The mobile phase for TCP was acetonitrile: $2 \%$ HAc $(80: 20, v / v)$. The flow rate was $1.0 \mathrm{~mL} \mathrm{~min}^{-1}$ and the wavelength was set at $290 \mathrm{~nm}$.

\section{Results and discussion}

\subsection{Structural and morphological characterization}

Fig. 1 depicts the SEM images of all the materials synthesized in each step. In Fig. $1 \mathrm{~A}$, the $\mathrm{Fe}_{3} \mathrm{O}_{4}$ particles possess homogeneous spherical structure with a mean diameter of $200 \mathrm{~nm}$ and disperse well in aqueous solution. With the immobilization of $\mathrm{SiO}_{2}$ coats, the particle sizes increase to $225-230 \mathrm{~nm}$ (Fig. 1B). Fig. 1C shows that uniform lamellar structured $\mathrm{Mg}-\mathrm{Al} \mathrm{LDH}$ nanoflakes are perpendicularly grafted to the surface of $\mathrm{Fe}_{3} \mathrm{O}_{4} @ \mathrm{SiO}_{2}$.

PDA layer was formed on the LDH nanosheets through autopolymerization of dopamine and Tris buffer was used to adjust the solution $\mathrm{pH}$ [26]. The prevalent view of coating mechanism of dopamine is that dopamine is oxidized to dopamine-quinine follow by cyclizing to leukodopaminechrome in alkaline conditions. Then, the dopamine monomer translates into 5,6-dihydroxyindole through a series of oxidation and rearrangement, and polymerize via aryl-aryl linkages to form PDA $[31,27]$. The adhesion of PDA may be due to the formation of $-\mathrm{COO}-\mathrm{H}_{3} \mathrm{~N}^{+}$- ion pairs [32]. In addition, the catechol groups of dopamine may also bond with the hydroxyl groups on the LDH surface through dehydration [33]. As shown in Fig. 1D, after coating with PDA on $\mathrm{Fe}_{3} \mathrm{O}_{4} @ \mathrm{SiO}_{2} @ \mathrm{Mg}-\mathrm{Al}$

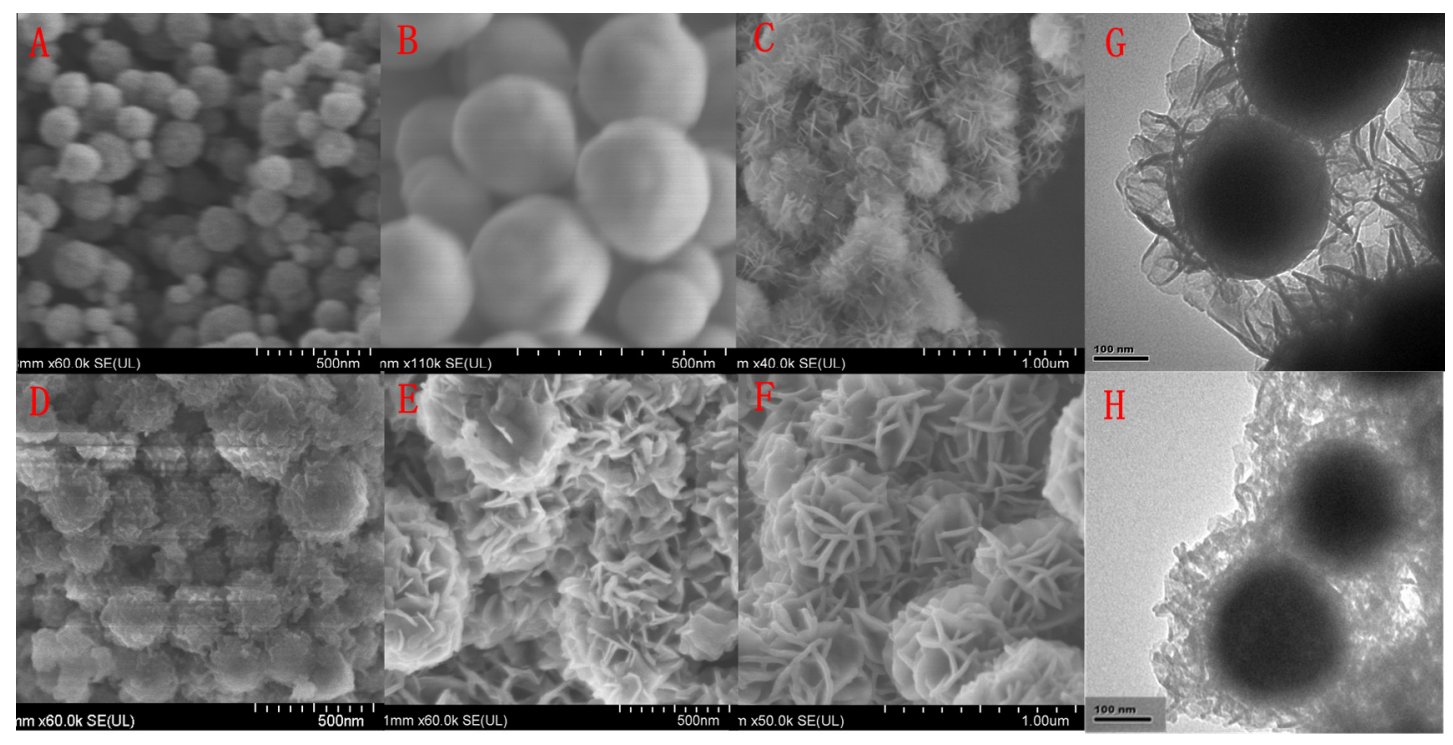

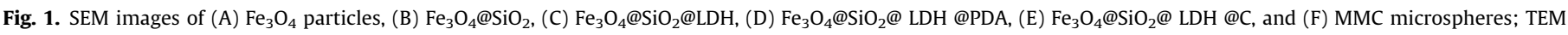
images of $(\mathrm{G}) \mathrm{Fe}_{3} \mathrm{O}_{4} @ \mathrm{SiO}_{2} @ \mathrm{LDH}$ and $(\mathrm{H}) \mathrm{MMC}$. 
LDH microspheres, the nanoflake structure disappears but the size of the microspheres does not change. The flowerlike structure appears again after carbonization of PDA coat (Fig. 1E), and keeps unchanged with the removal of $\mathrm{LDH}$ template (Fig. 1F). Fig. 1H shows that the flower like carbon shell is perpendicularly grafted to the surface of $\mathrm{Fe}_{3} \mathrm{O}_{4} @ \mathrm{SiO}_{2}$.

The crystal phases of the samples are investigated by XRD analysis. Fig. 2 depicts the XRD data for the microspheres at various stages. All the curves show that the magnetic core at different stages is face-centered cubic $\mathrm{Fe}_{3} \mathrm{O}_{4}$ (JCPDS card 19-629). After coating with the silica layer (curve b), the broad peak at $2 \theta$ values of $26.79^{\circ}$ can be assigned to amorphous $\mathrm{SiO}_{2}$. For $\mathrm{Fe}_{3} \mathrm{O}_{4} @ \mathrm{SiO}_{2} @ \mathrm{Mg}-\mathrm{Al}$ LDH microspheres (curve c), the increased peaks at $2 \theta$ values of $10.25^{\circ}, 23.01^{\circ}, 38.43^{\circ}$ and $61.77^{\circ}$ can be ascribed to the characteristic peaks of high crystallinity $\mathrm{LDH}$ shell. The XRD pattern of $\mathrm{Fe}_{3} \mathrm{O}_{4} @ \mathrm{SiO}_{2} @ \mathrm{LDH} @ P D A$ (curve d) and $\mathrm{Fe}_{3} \mathrm{O}_{4} @ \mathrm{SiO}_{2} @ L D H @ C$ (curve e) is very similar to that of $\mathrm{Fe}_{3} \mathrm{O}_{4} @ \mathrm{SiO}_{2} @ \mathrm{LDH}$, which indicates that the amorphous PDA coating and lower graphitized carbon do not change the crystalline phase of $\mathrm{Fe}_{3} \mathrm{O}_{4} @ \mathrm{SiO}_{2} @ \mathrm{LDH}$. The characteristic peaks of LDH were not observed in the XRD pattern of MMC (curve f), indicating that the $\mathrm{LDH}$ template was completely dissolved after being etched with hydrochloric acid.

The pore structure and specific surface area of MMC were determined by nitrogen adsorption method. Fig. 3 displays the $\mathrm{N}_{2}$ sorption-desorption isotherms and the corresponding pore-size distribution curves for MMC. The adsorption isotherm exhibits IV-type with a H3-type hysteresis loops indicating that the pore size is close to the mesoporous. The Brunauer-Emmett-Teller (BET) surface area and total pore volume are calculated to be $90.3 \mathrm{~m}^{2} \mathrm{~g}^{-1}$ and $0.22 \mathrm{~cm}^{3} \mathrm{~g}^{-1}$, respectively. The average pore size calculated from desorption branch of the $\mathrm{N}_{2}$ isotherm by $\mathrm{BJH}$ (Barrett-Joyner-Halenda) method is $3.8 \mathrm{~nm}$.

Fig. 4A shows the FTIR spectra of the obtained microspheres at different stages. In the spectrum of $\mathrm{Fe}_{3} \mathrm{O}_{4}$, the peaks observed at $585 \mathrm{~cm}^{-1}$ can be associated with $\mathrm{Fe}-\mathrm{O}$ vibration [29]. The adsorption peak at $1400 \mathrm{~cm}^{-1}$ is related to the vibration of $\mathrm{COO}^{-}$groups from citrate modified on $\mathrm{Fe}_{3} \mathrm{O}_{4}$ surface, and the broad peak at $1626 \mathrm{~cm}^{-1}$ is corresponding to the vibration of overlapping $\mathrm{COO}^{-}$ and $\mathrm{O}-\mathrm{H}$ groups [34]. The peak at $3434 \mathrm{~cm}^{-1}$ can be assigned to the surface-sorbed water and hydroxyl groups [35]. The Fe-O vibration is observed in all the other as-prepared materials, but the intensity of this peak decreases clearly due to the

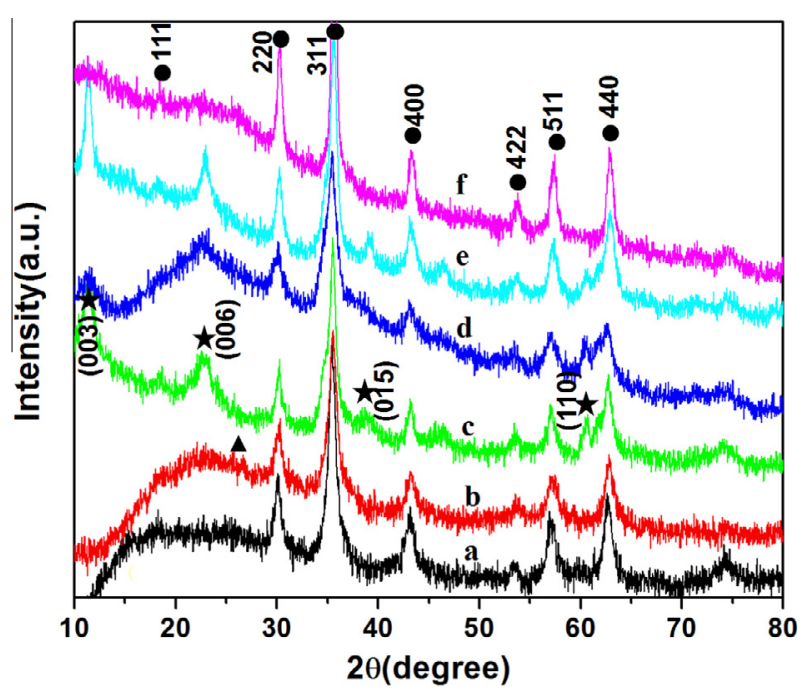

Fig. 2. XRD patterns of all the magnetic materials prepared in each step: (a) $\mathrm{Fe}_{3} \mathrm{O}_{4}$ (b) $\mathrm{Fe}_{3} \mathrm{O}_{4} @ \mathrm{SiO}_{2}$, (c) $\mathrm{Fe}_{3} \mathrm{O}_{4} @ \mathrm{SiO}_{2} @ \mathrm{LDH}$, (d) $\mathrm{Fe}_{3} \mathrm{O}_{4} @ \mathrm{SiO}_{2} @ \mathrm{LDH} @ P D A,(e) \mathrm{Fe}_{3} \mathrm{O}_{4} @ \mathrm{SiO}_{2}$ $@ \mathrm{LDH} @ \mathrm{C}$ and (f) MMC; diffraction peaks of $\bullet: \mathrm{Fe}_{3} \mathrm{O}_{4} ; \star$ : LDH; $\mathbf{\Delta}$ : amorphous silica.

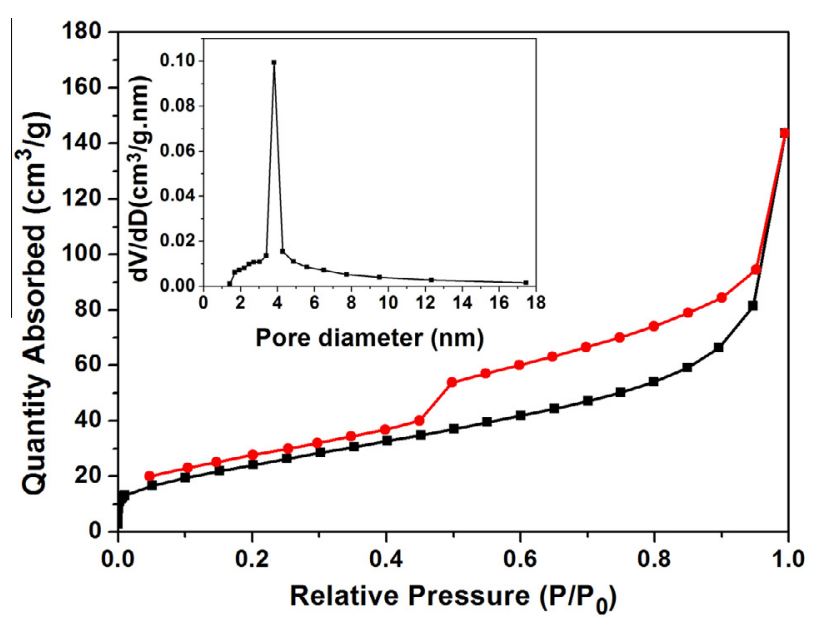

Fig. 3. Nitrogen adsorption-desorption isotherm of MMC (inset is the pore size distribution of MMC).

immobilization of $\mathrm{SiO}_{2}, \mathrm{LDH}$ and carbon coat. After coating with silica layer, the $\mathrm{Si}-\mathrm{O}-\mathrm{Si}$ absorption band at $1089 \mathrm{~cm}^{-1}$ is observed in the spectra of all silica-related materials [36]. Due to the introduction of LDH layer, the intensities of peaks at 3434 and $1626 \mathrm{~cm}^{-1}$ increase in the spectrum of $\mathrm{Fe}_{3} \mathrm{O}_{4} @ \mathrm{SiO}_{2} @ \mathrm{LDH}$. For $\mathrm{Fe}_{3} \mathrm{O}_{4} @ \mathrm{SiO}_{2} @$ LDH@PDA, signals around $1290 \mathrm{~cm}^{-1}$ may be the primary amine vibration from the PDA coating [29]. Typical peak around $1480 \mathrm{~cm}^{-1}$ resulting from the aromatic $\mathrm{C}-\mathrm{H}$ bending and might be the aliphatic primary amine vibration [37]. In addition, the band appears at $1508 \mathrm{~cm}^{-1}$ may belong to the $\mathrm{C}=\mathrm{C}$ stretching vibrations of aromatic ring of PDA coating. This peak is not observed in the spectra of $\mathrm{Fe}_{3} \mathrm{O}_{4} @ \mathrm{SiO}_{2} @ \mathrm{LDH} @ \mathrm{C}$ and MMC, suggesting successful carbonization of PDA coating. The adsorption bands corresponding to surface-sorbed water and hydroxyl groups still remain on the surface of MMC.

The magnetic properties of the as-synthesized microspheres were investigated using a vibrating sample magnetometer at room temperature. Fig. $4 \mathrm{~B}$ shows that the saturation magnetization of the microspheres decreased with the addition of silica, LDH and PDA layer, which can be explained by the increasing thickness of the nonmagnetic component. However, the saturation magnetization of the microspheres enhances after carbonization. The maximal saturation magnetization of $\mathrm{Fe}_{3} \mathrm{O}_{4} @ \mathrm{SiO}_{2} @ \mathrm{LDH} @ P D A$ (curve d), $\mathrm{Fe}_{3} \mathrm{O}_{4} @ \mathrm{SiO}_{2} @ \mathrm{LDH} @ \mathrm{C}$ (curve e) and MMC (curve f) particles is $8.24,12.32,16.99 \mathrm{emu} \mathrm{g}^{-1}$, respectively. This may attribute to the rise of the $\mathrm{Fe}_{3} \mathrm{O}_{4}$ density resulting from the carbonization of PDA coat and removal of LDH template.

XPS measurement was employed to investigate the elemental composition on the surface of $\mathrm{Fe}_{3} \mathrm{O}_{4} @ \mathrm{SiO}_{2} @ \mathrm{LDH}, \mathrm{Fe}_{3} \mathrm{O}_{4} @ \mathrm{SiO}_{2} @$ LDH@PDA, $\mathrm{Fe}_{3} \mathrm{O}_{4} @ \mathrm{SiO}_{2} @ \mathrm{LDH} @ \mathrm{C}$ and MMC materials. In Fig. 5A, the signals of $\mathrm{O} 1 \mathrm{~s}, \mathrm{Mg} 1 \mathrm{~s}$ and $\mathrm{Al} 2 \mathrm{p}$ in the curve of $\mathrm{Fe}_{3} \mathrm{O}_{4} @ \mathrm{SiO}_{2} @ \mathrm{LDH}$ (curve a) are observed at 539.95, 1308.76 and $79.95 \mathrm{eV}$, respectively, which suggests the appearance of $\mathrm{Mg}-\mathrm{Al} \mathrm{LDH}$ on the $\mathrm{Fe}_{3} \mathrm{O}_{4} @ \mathrm{SiO}_{2}$ nanoparticles. For $\mathrm{Fe}_{3} \mathrm{O}_{4} @ \mathrm{SiO}_{2} @ L D H @ P D A$ (curve b), the intensities of these signals weakened because of the dopamine modification. After the carbonization of PDA, the signals of $01 \mathrm{~s}$, $\mathrm{Mg} 1 \mathrm{~s}$ and $\mathrm{Al} 2 \mathrm{p}$ increase again due to the decrease of carbon layer thickness. The signals of Mg1s and Al2p could hardly be observed in the curve of MMC (curve d), which confirms the LDH nanosheets were completely dissolved and mesoporous structure generated. In addition, the signal of N1s appears after PDA coating (Fig. 5A). The nitrogen content on the surface of $\mathrm{Fe}_{3} \mathrm{O}_{4} @ \mathrm{SiO}_{2} @ \mathrm{LDH} @ P D A$, $\mathrm{Fe}_{3} \mathrm{O}_{4} @ \mathrm{SiO}_{2} @ \mathrm{LDH} @ \mathrm{C}$ and $\mathrm{MMC}$ were calculated to be $8.27 \mathrm{wt} \%$, $6.6 \mathrm{wt} \%$ and $9.72 \mathrm{wt} \%$, respectively. For MMC, the N1s high-resolution spectrum could be identified into two component peaks at the 

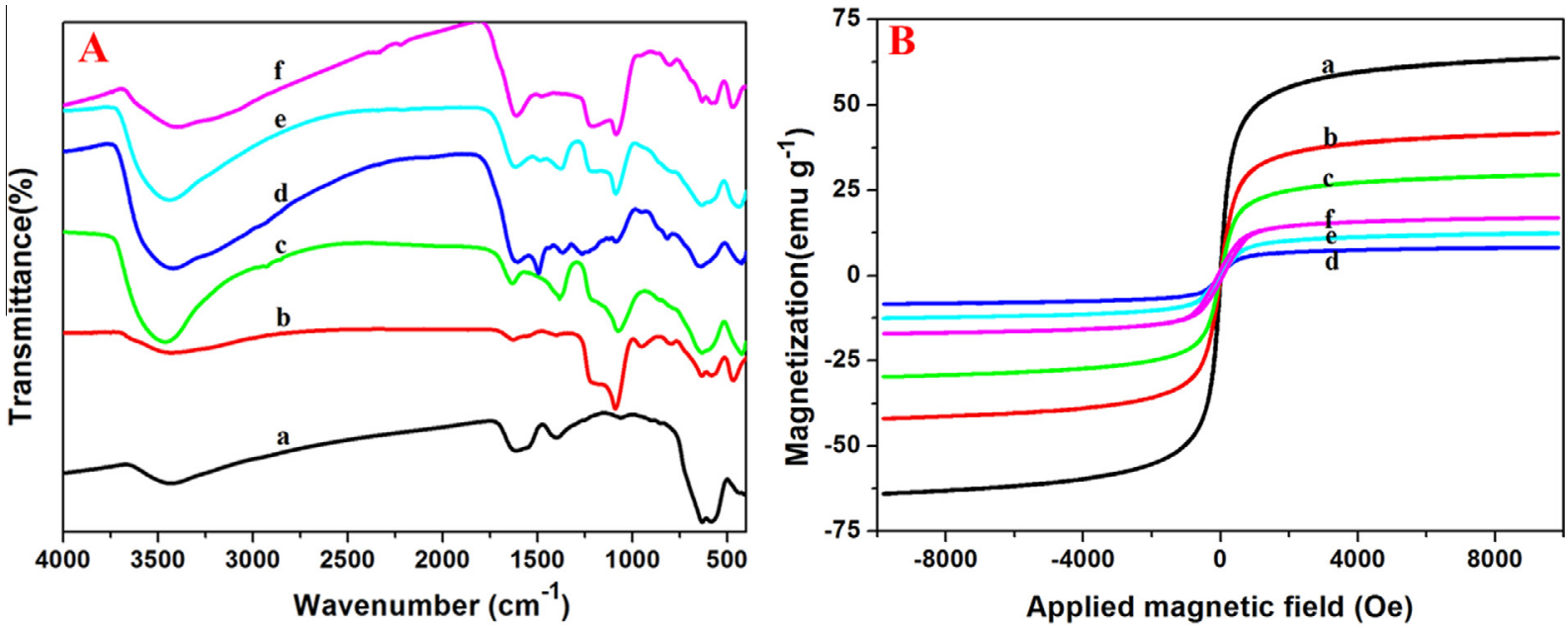

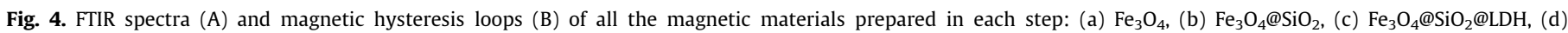
$\mathrm{Fe}_{3} \mathrm{O}_{4} @ \mathrm{SiO}_{2} @ \mathrm{LDH} @ P D A,(\mathrm{e}) \mathrm{Fe}_{3} \mathrm{O}_{4} @ \mathrm{SiO}_{2} @ \mathrm{LDH} @ \mathrm{C}$ and (f) MMC.
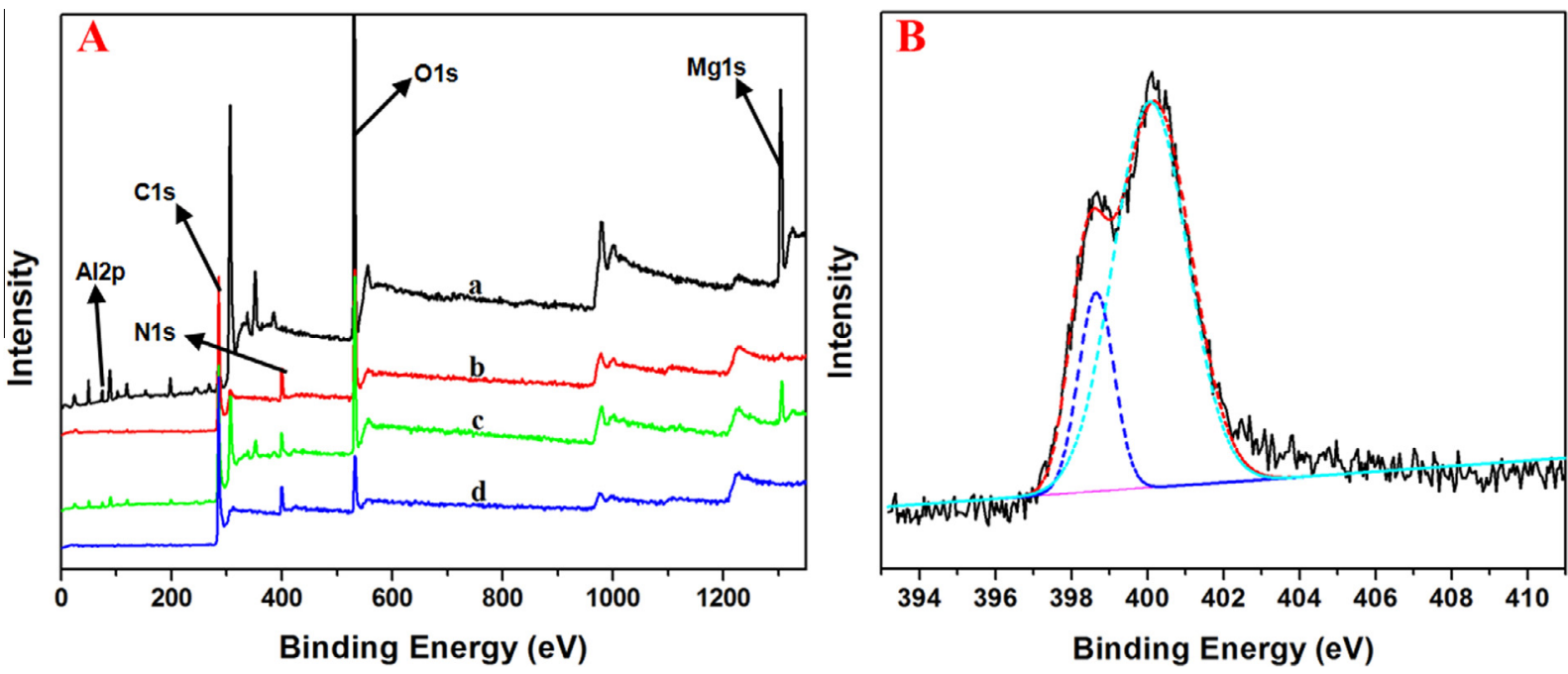

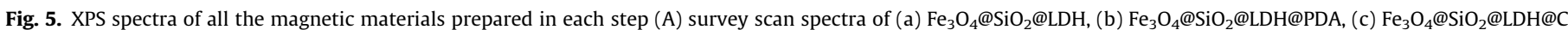
and (d) MMC particles; (B) high-resolution N1s spectra of MMC particles.

Binding Energy of 400.2 and $398.4 \mathrm{eV}$ (Fig. 5B), relating to $\mathrm{C}-\mathrm{N}$ and $\mathrm{C}=\mathrm{N}[38,39]$, respectively, indicating PDA has been transformed into N-doped carbon after pyrolysis. The XPS results are consistent with those obtained in SEM, XRD and FTIR analysis.

\subsection{Adsorption behavior and mechanism of TCP on MMC}

\subsubsection{Effect of $p H$}

Fig. $6 \mathrm{~A}$ displays the influence of the initial solution $\mathrm{pH}$ on the removal of TCP by MMC. The adsorption of TCP is high and increases slightly in acid solution. The highest uptake is observed at $\mathrm{pH} 4$. As solution $\mathrm{pH}$ is higher than 4, TCP uptake decreases promptly. Similar phenomenon has been reported in previous researches $[40,41]$. The higher adsorption performance in acid condition than alkaline condition may be related to the pKa of TCP $(\mathrm{pKa}=6.15)$ and zero point potential of MMC. At low pH, the majority of TCP appears neutral and unionized [40]. When solution $\mathrm{pH}$ is higher than $\mathrm{pH}_{\mathrm{pKa}}$, TCP ionized gradually. The $\zeta$-potential of MMC was measured at different solution pHs. Fig. 6B shows that the zero point potential of MMC was found at about $\mathrm{pH}$ 3.5. At $\mathrm{pH} 3.5-4$, both TCP and the oxygen species on MMC surface are neutral, which favors the $\pi-\pi$ stacking interaction and/or hydrophobic interactions between TCP and MMC. As solution pH was lower than $\mathrm{pH}$ 3.5, the surface of MMC was positively charged. Therefore, the hydrophobic interaction between TCP and MMC was weakened. In neutral and alkaline solution, both TCP and MMC surface are negatively charged. Electrostatic repulsions between the negative surface of MMC and anionic TCP are expected, leading to decreased adsorption of TCP on MMC with the increase of solution $\mathrm{pH}$.

\subsubsection{Adsorption kinetics studies}

The kinetics of TCP adsorption onto MMC was analyzed using both the pseudo-first-order and pseudo-second order kinetic models. The pseudo-first-order kinetic model is defined as follows:

$\ln \left(q_{e}-q_{t}\right)=\ln q_{e}-k_{1} t$

where $q_{e}\left(\mathrm{mg} \mathrm{g}^{-1}\right)$ and $q_{t}\left(\mathrm{mg} \mathrm{g}^{-1}\right)$ are the amounts of TCP adsorbed at equilibrium and any time $t(\mathrm{~h})$, respectively, and $k_{1}\left(\mathrm{~h}^{-1}\right)$ is the adsorption rate constant.

The pseudo-second-order constants were calculated according to Eq. (2): 

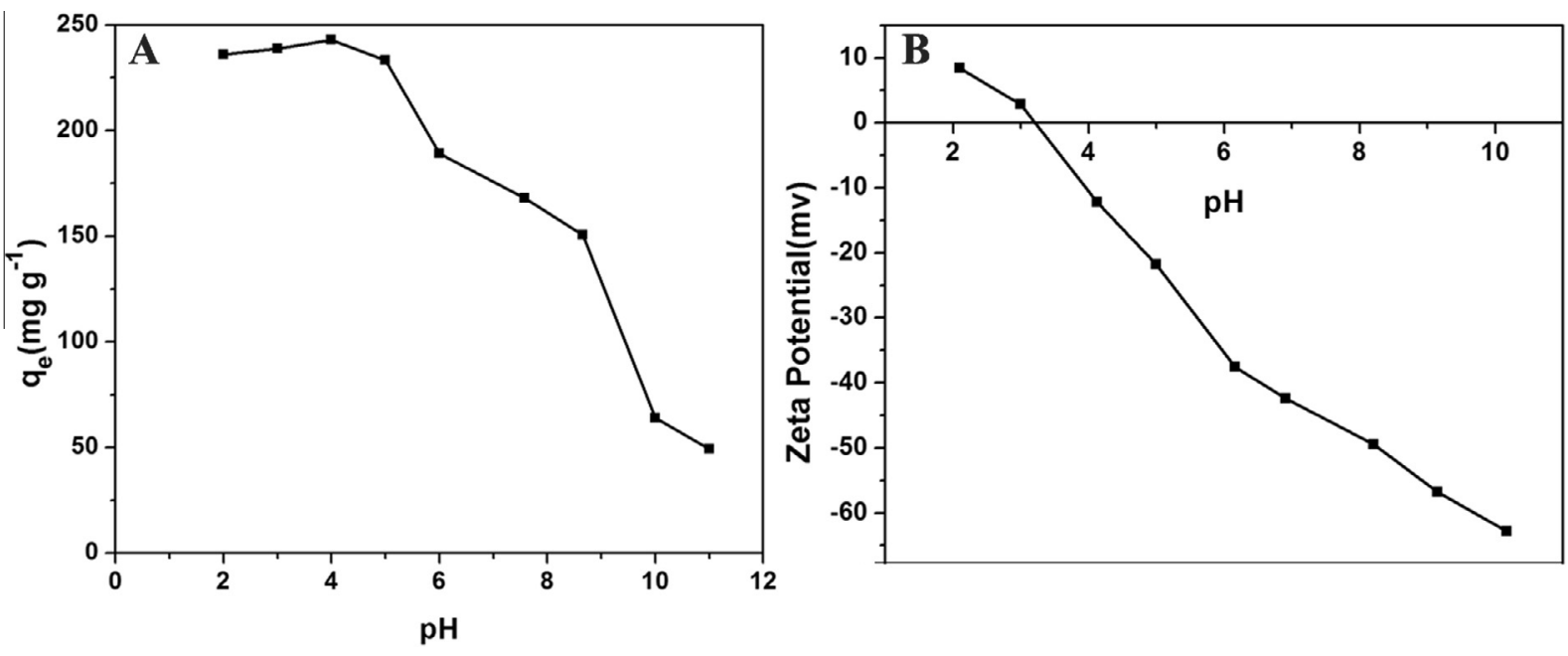

Fig. 6. Effect of solution $\mathrm{pH}(\mathrm{A})$ and MMC zeta potential (B) on TCP removal.

$\frac{t}{q_{t}}=\frac{1}{k_{2} q_{e}^{2}}+\frac{1}{q_{e}} t$

where $k_{2}\left(\mathrm{~g} \mathrm{mg}^{-1} \mathrm{~h}^{-1}\right)$ is the pseudo-second-order rate constant.

As shown in Fig. 7A, TCP adsorption was fast in the first $3 \mathrm{~h}$, after that increased slowly with time and reached a constant value in $8 \mathrm{~h}$. Similar trend was observed in the adsorption of TCP on polyester membranes and oil palm empty fruit bunch-based activated carbon $[42,43]$. The kinetic parameters and correlation coefficient $\left(R^{2}\right)$ obtained for the plots are given in Table 1 . As a result, the $R^{2}$ value of pseudo-second-order kinetic model is about 0.99 and the calculated $q_{e, \text { cal }}$ is very close to the experimental $q_{e, \text { exp }}$, demonstrating that the kinetics data fits well with the pseudo-secondorder kinetic model. Similar phenomenon has been reported in the adsorption of TCP on zeolite and cob carbon $[44,45]$.

\subsubsection{Adsorption isotherm analysis}

The effect of solution temperature on TCP adsorption was studied by varying the adsorption temperature at 303, 313 and $323 \mathrm{~K}$, respectively. In Fig. 7B, the adsorption capacity of MMC to TCP increased with increasing solution temperature, indicating the endothermic nature of the adsorption process. Langmuir and Freundlich isotherm models were used to investigate the relationship between the adsorption quantity of TCP onto MMC and its equilibrium concentration in water solution. The Langmuir model is based on the assumption that the adsorption is in monomolecular type and it happens on a homogeneous surface with all the adsorption sites possessing identical adsorbate affinity, while the Freundlich isotherm model is often applicable to a heterogeneous adsorption surfaces with multilayer adsorption [46]. The Langmuir and Freundlich isotherm are expressed in Eqs. (3) and (4), respectively:

$\frac{c_{e}}{q_{e}}=\frac{c_{e}}{Q_{0}}+\frac{1}{Q_{0} b}$

where $q_{e}\left(\mathrm{mg} \mathrm{g}^{-1}\right)$ is the equilibrium absorption capacity, $c_{e}$ $\left(\mathrm{mg} \mathrm{L}^{-1}\right)$ is the equilibrium TCP concentration, $Q_{0}\left(\mathrm{mg} \mathrm{g}^{-1}\right)$ and $b$ $\left(\mathrm{L} \mathrm{mg}^{-1}\right)$ is the Langmuir constant related to the maximum adsorption capacity and the free energy of adsorption, respectively.

$\ln q_{e}=\ln k+\frac{1}{n} \ln c_{e}$

where $k\left(\mathrm{mg} \mathrm{g}^{-1}\right)$ is the Freundlich constant related to the adsorption capacity and $n$ refers to the empirical parameter.
Correlation coefficient $\left(R^{2}\right)$ values and constants obtained from the two isotherm models are listed in Table 2. The adsorption data fits well to Freundlich isotherm model with a higher $R^{2}$ value at all solution temperatures studied. The $1 / n$ value obtained from the Freundlich model is below 1 representing that adsorption of TCP on the MMC was favorable. The phenomenon that Freundlich model gives a better fit than Langmuir model in accordance with some works reported previous [47].

Because the experimental data does not fit well to Langmuir model, we compare the adsorption ability of MMC to TCP with other adsorbents reported in literature according to the adsorption capacity calculated at certain initial concentration instead of the monolayer adsorption value calculated by the Langmuir equation. Table 3 summarized the comparison of TCP adsorption capacity on various adsorbents. When the TCP initial concentration was 20 and $100 \mathrm{mg} \mathrm{L}^{-1}$, the adsorption capacity of MMC to TCP was 210 and $587 \mathrm{mg} \mathrm{g}^{-1}$, respectively, which were much higher than those obtained on other carbon-based materials reported in literature $[43,40,48-50]$. For activated carbon, the largest surface area is made up of micro pores (with a radius of less than $1 \mathrm{~nm}$ ), and the micro pores are easily clogged up in aqueous solution, which makes the adsorptive sites unavailable to adsorbates. The average pores size of MMC is $3.8 \mathrm{~nm}$ (meso pores) and the flowerlike morphology carbon shell on $\mathrm{Fe}_{3} \mathrm{O}_{4} @ \mathrm{SiO}_{2}$ core surface is relatively thin, therefore, TCP can migrate from the solution through the pore channels to reach most adsorptive sites. This is the possible reason for the much higher adsorption ability of MMC to TCP than that of activated carbon. In addition, we also made a comparison of the adsorption ability of MMC with directly synthesized magnetic carbon spherical (denoted as DMC) by coating the carbon shell (dopamine as carbon source) in the absence of inorganic layered sacrificed scaffold. As the initial concentration of TCP was $20 \mathrm{mg} \mathrm{L}^{-1}$, the adsorption capacity was calculated to be $141 \mathrm{mg} \mathrm{g}^{-1}$, which was lower than that of MMC. We can conclude that both the total surface areas and pore size distribution affect the adsorption capacity of carbon materials.

\subsubsection{Adsorption thermodynamics studies}

Thermodynamic parameters including Gibbs free energy change $\left(\Delta G^{0}\right)$, enthalpy $\left(\Delta H^{0}\right)$, and entropy $\left(\Delta S^{0}\right)$ were calculated by the following equations:

$\ln K_{d}=\frac{\Delta S^{0}}{R}-\frac{\Delta H^{0}}{R T}$ 

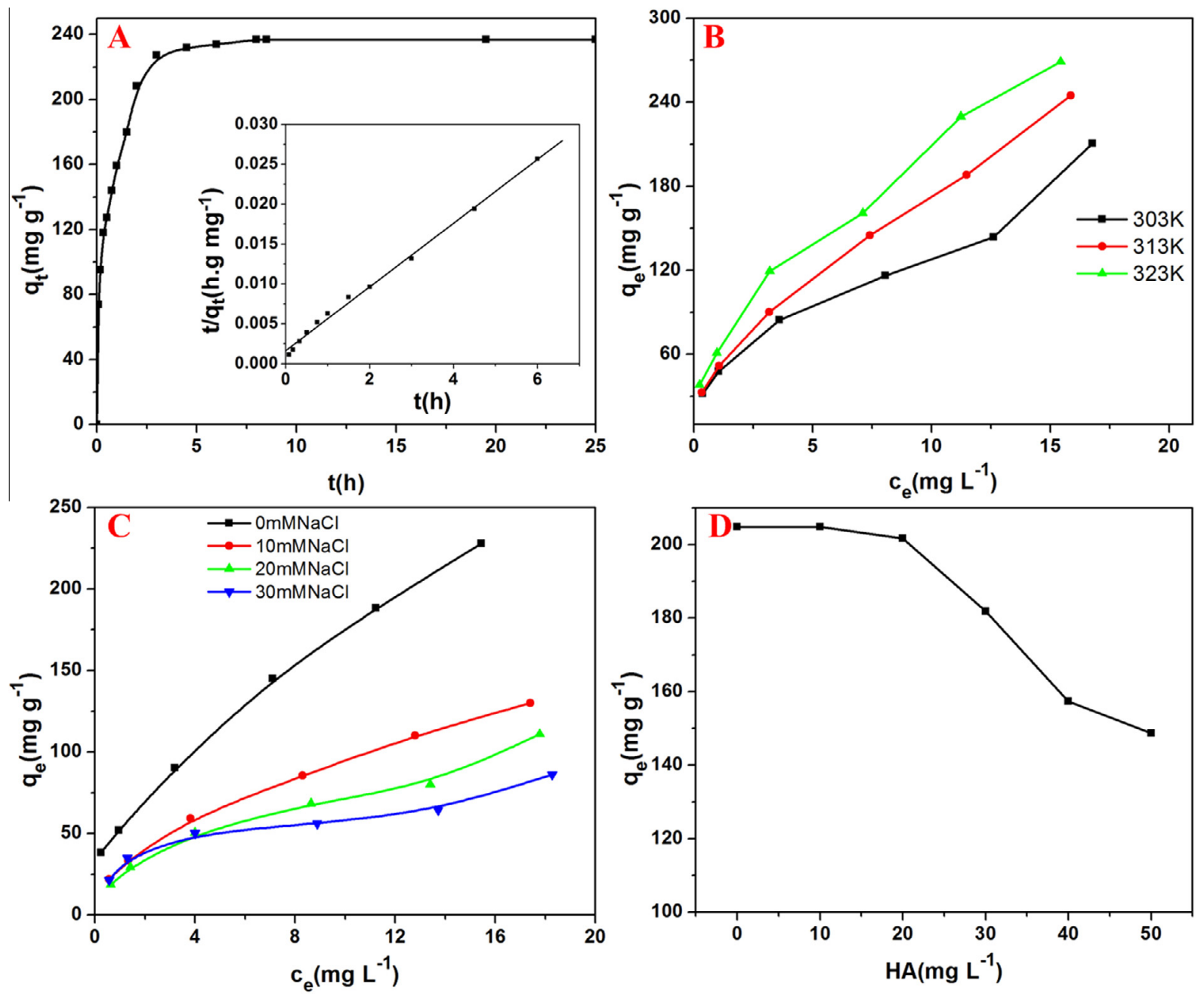

Fig. 7. Effect of reaction time (inset describes the pseudo-second-order kinetic) (A), solution temperature (B), ionic strength (C), and HA (D) on TCP removal.

Table 1

Kinetic parameters for TCP adsorption on MMC.

\begin{tabular}{|c|c|c|c|c|c|c|c|}
\hline & \multirow{2}{*}{$\begin{array}{l}q_{e, \exp } \\
\left(\mathrm{mg} \mathrm{g}^{-1}\right)\end{array}$} & \multicolumn{3}{|c|}{ Pseudo-first-order } & \multicolumn{3}{|c|}{ Pseudo-second-order } \\
\hline & & $\begin{array}{l}q_{e, \text { cal }} / \\
\mathrm{mg} \mathrm{g}^{-1}\end{array}$ & $\begin{array}{l}k_{1} / \\
\mathrm{h}^{-1}\end{array}$ & $R^{2}$ & $\begin{array}{l}q_{e, c a l} / \\
\mathrm{mg} \mathrm{g}^{-1}\end{array}$ & $\begin{array}{l}k_{2} / \\
\mathrm{mmol}^{-1} \mathrm{~h}^{-1}\end{array}$ & $R^{2}$ \\
\hline TCP & 240 & 148 & 0.72 & 0.96 & 250 & 0.01 & 0.99 \\
\hline
\end{tabular}

Table 2

Constants and correlation coefficients of Langmuir and Freundlich isotherm models for adsorption of TCP on prepared MMC.

\begin{tabular}{|c|c|c|c|c|c|c|}
\hline \multirow{2}{*}{$\begin{array}{l}\text { Solution } \\
\text { temperature } \\
\text { (K) }\end{array}$} & \multicolumn{3}{|c|}{$\begin{array}{l}\text { Langmuir } \\
\text { isotherm model }\end{array}$} & \multicolumn{3}{|l|}{$\begin{array}{l}\text { Freundlich isotherm } \\
\text { model }\end{array}$} \\
\hline & $\begin{array}{l}\mathrm{Q}_{0} / \\
\mathrm{mg} \mathrm{g}^{-1}\end{array}$ & $\begin{array}{l}b / \\
\mathrm{L} \mathrm{mg}^{-1}\end{array}$ & $R^{2}$ & $\begin{array}{l}K / \\
\left(\mathrm{mg} \mathrm{g}^{-1}\left(\mathrm{~L} \mathrm{mg}^{-1}\right)^{1 / n}\right)\end{array}$ & $1 / n$ & $R^{2}$ \\
\hline 303 & 243.8 & 0.212 & 0.861 & 48.139 & 0.463 & 0.991 \\
\hline 313 & 294.1 & 0.188 & 0.899 & 53.413 & 0.517 & 0.992 \\
\hline 323 & 312.5 & 0.248 & 0.918 & 69.387 & 0.472 & 0.989 \\
\hline
\end{tabular}

$\Delta G^{0}=\Delta H^{0}-T \Delta S^{0}$

where $K_{d}$ is the distribution coefficient, equal to $q_{e} / c_{e}, R$ $\left(8.314 \mathrm{~J} \mathrm{~mol}^{-1} \mathrm{~K}^{-1}\right)$ is the universal gas constant, $T(\mathrm{~K})$ is the temperature. The values of $\Delta G^{0}, \Delta H^{0}$, and $\Delta S^{0}$ for the adsorption
Table 3

Comparison of adsorption capacity on different adsorbents.

\begin{tabular}{llll}
\hline Materials & $\begin{array}{l}Q_{e}\left(\mathrm{mg} \mathrm{g}^{-1}\right) \\
C_{0}=20 \mathrm{mg} \\
\mathrm{L}^{-1}\end{array}$ & $\begin{array}{l}Q_{e}\left(\mathrm{mg} \mathrm{g}^{-1}\right) \\
C_{0}=100 \mathrm{mg} \mathrm{L}^{-1}\end{array}$ & Refs. \\
\hline MMC & 210 & 587 & This \\
& & & work \\
Magnetic imprinted polymers & - & 170 & {$[48]$} \\
Multi-walled carbon nanotubes & - & 125 & {$[49]$} \\
Coconut husk-based activated & 175 & - & {$[50]$} \\
$\quad$ carbon & 50 & - & {$[40]$} \\
Graphene & 10 & - & {$[40]$} \\
Graphene oxide & - & 80 & {$[43]$} \\
EFB-based activated carbon & 190 & - & {$[55]$} \\
Ash & 20 & 100 & {$[41]$} \\
Commercial activated carbon & 20 & & \\
\hline
\end{tabular}

of TCP onto MMC at different temperatures are listed in Table 4. The negative value of Gibbs energy suggests that TCP adsorption on MMC is spontaneous. The increase of $\Delta G^{0}$ absolute value with solution temperatures indicates that the adsorption is favorable at higher temperature [51]. The positive values of $\Delta H^{0}$ and $\Delta S^{0}$ show that the adsorption is endothermic and random at the solid-solution interface. If the value of $\Delta H^{0}$ is higher than $40 \mathrm{~kJ} \mathrm{~mol}^{-1}$, the adsorption process is supposed to proceed via chemisorption; if the $\Delta H^{0}$ value is less than $40 \mathrm{~kJ} \mathrm{~mol}^{-1}$, the adsorption process is of physisorption nature [47]. The value of $\Delta H^{0}$ is $13 \mathrm{~kJ} \mathrm{~mol}^{-1}$ in this 
Table 4

Thermodynamic parameters of the TCP adsorption on MMC.

\begin{tabular}{lllll}
\hline$\Delta H^{0}\left(\mathrm{~kJ} \mathrm{~mol}^{-1}\right)$ & $\Delta S^{0}\left(\mathrm{~J} \mathrm{~mol}^{-1} \mathrm{~K}^{-1}\right)$ & \multicolumn{4}{l}{$\Delta G^{0} / \mathrm{kJ} \mathrm{mol}^{-1}$} \\
\cline { 2 - 5 } & & $303 \mathrm{~K}$ & $313 \mathrm{~K}$ & $323 \mathrm{~K}$ \\
\hline 13.317 & 65.089 & -6.404 & -7.055 & -7.706 \\
\hline
\end{tabular}

study, implying that TCP adsorption on MMC is likely due to physisorption.

\subsubsection{Effect of ionic strength}

The effect of ionic strength on TCP adsorption was investigated with $\mathrm{NaCl}$ concentrations ranging from $0 \mathrm{mM}$ to $30 \mathrm{mM}$. The results from Fig. 7C show that the adsorption capacity decreased with increased $\mathrm{NaCl}$ concentrations. This phenomenon suggests that electrostatic interactions and ionic adsorption maybe also play a role between TCP and MMC [52].

\subsubsection{Effect of humic acids}

Humic Acids (HAs), a typical natural organic matter (NOM), is common in environmental water samples and would interfere with the adsorption of target compounds. Many organic compounds can be adsorbed on HAs due to their abundant functional groups [53]. The effect of HAs on TCP adsorption was tested with HAs concentrations ranging from 0 to $50 \mathrm{mg} \mathrm{L}^{-1}$. Fig. 7D shows that the absorption ability of MMC to TCP was unchanged as HAs concentration was lower than $10 \mathrm{mg} \mathrm{L}^{-1}$; and the adsorption capacity decreased by $1.57 \%$ when HAs concentration reached $20 \mathrm{mg} \mathrm{L}^{-1}$, after which sharp decrease of TCP uptake was observed. This result suggests that there is competitive adsorption toward TCP between HAs and MMC sorbent. In surface water samples, the concentration of HAs generally ranges from 1 to $5 \mathrm{mg} \mathrm{L}^{-1}$ [54], in which TCP adsorption on MMC is hardly influenced by HAs. Therefore, we expect that the adsorption process of TCP onto MMC would not be affected by natural organic matter in real water samples.

\section{Conclusions}

Magnetic mesoporous carbon nanomaterials with flowerlike morphology were synthesized and applied to adsorb TCP from aqueous solution in this study. This material exhibits excellent adsorption performance for TCP attributing to the high specific surface area and mesoporous channels generated from the carbon shell. The adsorption capacity of TCP on MMC was obviously higher than those obtained on other carbon-based materials reported in literature. Lower concentration of $\mathrm{NaCl}$ salts and HAs have insignificant influence on TCP adsorption. In conclusion, the MMC prepared in this paper can be regarded as an efficient adsorbent to remove TCP from aquatic environment.

\section{Acknowledgments}

This work was jointly supported by National Basic Research Program of China (2011CB936001); National Natural Science Foundation of China $(21277152,21277002,41222026)$.

\section{References}

[1] J. Lee, S. Yoon, T. Hyeon, S.M. Oh, K.B. Kim, Chem. Commun. (1999) 2177-2178. [2] R.K. Dash, G. Yushin, Y. Gogotsi, Micropor. Mesopor. Mater. 86 (2005) 50-57.

[3] Z.K. Sun, Y. Liu, B. Li, J. Wei, M.H. Wang, Q. Yue, Y.H. Deng, S. Kaliaguine, D.Y. Zhao, ACS Nano 7 (2013) 8706-8714.

[4] A.S. Marriott, E. Bergström, A.J. Hunt, J. Thomas-Oates, J.H. Clark, RSC Adv. 4 (2014) 222-228.
[5] N.F. Nejad, E. Shams, M.K. Amini, J.C. Bennett, Fuel Process. Technol. 106 (2013) 376-384.

[6] L.H. Zhang, Q. Sun, D.H. Liu, A.H. Lu, J. Mater. Chem. A 1 (2013) 9477-9483.

[7] B. Guan, X. Wang, Y. Xiao, Y. Liu, Q. Huo, Nanoscale 5 (2013) 2469-2475.

[8] L.J. You, S. Xu, W.F. Ma, D. Li, Y.T. Zhang, J. Guo, J.J. Hu, C.C. Wang, Langmuir 28 (2012) 10565-10572.

[9] C.R. Zhao, W.K. Wang, Z.B. Yu, H. Zhang, A.B. Wang, Y.S. Yang, J. Mater. Chem. 20 (2010) 976-980.

[10] A. Vinu, S. Anandan, C. Anand, P. Srinivasu, K. Ariga, T. Mori, Micropor Mesopor. Mater. 109 (2008) 398-404.

[11] Y. Zhang, S. Xu, Y. Luo, S. Pan, H. Ding, G. Li, J. Mater. Chem. 21 (2011) 3664-3671.

[12] J. Górka, M. Jaroniec, Carbon 49 (2011) 154-160.

[13] Y. Deng, D. Qi, C. Deng, X. Zhang, D. Zhao, J. Am. Chem. Soc. 130 (2008) 28-29.

[14] Y. Deng, Y. Cai, Z. Sun, J. Liu, C. Liu, J. Wei, W. Li, C. Liu, Y. Wang, D. Zhao, J. Am. Chem. Soc. 132 (2010) 8466-8473.

[15] M. Shao, F. Ning, J. Zhao, M. Wei, D.G. Evans, X. Duan, J. Am. Chem. Soc. 134 (2012) 1071-1077.

[16] F. Mi, X. Chen, Y. Ma, S. Yin, F. Yuan, H. Zhang, Chem. Commun. 47 (2011) $12804-12806$.

[17] M. Shao, F. Ning, Y. Zhao, J. Zhao, M. Wei, D.G. Evans, X. Duan, Chem. Mater. 24 (2012) 1192-1197.

[18] Y. Liu, N. Wang, L. Diestel, F. Steinbach, J. Caro, Chem. Commun. 50 (2014) 4225-4227.

[19] C. Chen, P. Wang, T.T. Lim, L. Liu, S. Liu, R. Xu, J. Mater. Chem. A 1 (2013) 3877-3880.

[20] S. Tang, H.K. Lee, Anal. Chem. 85 (2013) 7426-7433.

[21] L. Tong, J. Shi, X. Ren, Q. Li, H. Ding, H. Yang, J. Nanopart. Res. 15 (2013) 1-9.

[22] J.E. Lee, S.H. Yu, D.J. Lee, D.C. Lee, S.I. Han, Y.E. Sung, T. Hyeon, Energy Environ. Sci. 5 (2012) 9528.

[23] X.B. Zhang, H.W. Tong, S.M. Liu, G.P. Yong, Y.F. Guan, J. Mater. Chem. A 1 (2013) 7488-7493.

[24] R. Subramanyam, I.M. Mishra, Bioresour. Technol. 99 (2008) 4147-4157.

[25] J.A. Swenberg, B.C. Moeller, K. Lu, J.E. Rager, R.C. Fry, T.B. Starr, Toxicol. Pathol. 41 (2013) 181-189.

[26] H. Lee, S.M. Dellatore, W.M. Miller, P.B. Messersmith, Science 318 (2007) 426-430.

[27] C. Lei, F. Han, D. Li, W.C. Li, Q. Sun, X.Q. Zhang, A.H. Lu, Nanoscale 5 (2013) 1168-1175.

[28] R. Liu, S.M. Mahurin, C. Li, R.R. Unocic, J.C. Idrobo, H. Gao, S.J. Pennycook, S. Dai, Angew. Chem. Int. Ed. 50 (2011) 6799-6802.

[29] T. Zeng, X. Zhang, H. Niu, Y. Ma, W. Li, Y. Cai, Appl. Phys. B 134-135 (2013) 26-33.

[30] Y.S. Wang, X.O. Shan, M.H. Feng, G.C. Chen, Z.G. Pei, B. Wen, T. Liu, Y.N. Xie, G. Owens, Environ. Sci. Technol. 43 (2009) 5726-5731.

[31] E. Amstad, A.U. Gehring, H. Fischer, V.V. Nagaiyanallur, G. Hahner, M. Textor, E. Reimhult, J. Phys. Chem. C 115 (2011) 683-691.

[32] J.Y. Si, H. Yang, Mater. Chem. Phys. 128 (2011) 519-524.

[33] J.L. Dalsin, L.J. Lin, S. Tosatti, J. Voros, M. Textor, P.B. Messersmith, Langmuir 21 (2005) 640-646.

[34] T. Zeng, X. Zhang, Y. Ma, S. Wang, H. Niu, Y. Cai, Chem. Commun. 49 (2013) 6039-6041.

[35] H. Niu, Y. Wang, X. Zhang, Z. Meng, Y. Cai, ACS Appl. Mater. Interfaces 4 (2012) $286-295$.

[36] X.L. Zhang, H.Y. Niu, W.H. Li, Y.L. Shi, Y.Q. Cai, Chem. Commun. 47 (2011) 4454-4456.

[37] M. Sureshkumar, C.K. Lee, Carbohydr. Polym. 84 (2011) 775-780.

[38] Y. Ma, C. Zhang, G. Ji, J.Y. Lee, J. Mater. Chem. 22 (2012) 7845-7850.

[39] L. Zhao, Y.S. Hu, H. Li, Z.X. Wang, L.Q. Chen, Adv. Mater. 23 (2011) 1385-1388.

[40] Z.G. Pei, L.Y. Li, L.X. Sun, S.Z. Zhang, X.O. Shan, S. Yang, B. Wen, Carbon 51 (2013) 156-163.

[41] M. Radhika, K. Palanivelu, J. Hazard. Mater. 138 (2006) 116-124.

[42] S.P. Malinga, O.A. Arotiba, R.W.M. Krause, S.F. Mapolie, M.S. Diallo, B.B. Mamba, J. Nanopart. Res. 15 (2013) 1-15.

[43] I.A. Tan, A.L. Ahmad, B.H. Hameed, J. Hazard. Mater. 164 (2009) 473-482.

[44] A. Kuleyin, J. Hazard. Mater. 144 (2007) 307-315.

[45] M. Sathishkumar, A.R. Binupriya, D. Kavitha, R. Selvakumar, R. Jayabalan, J.G. Choi, S.E. Yun, Chem. Eng. J. 147 (2009) 265-271.

[46] X. Zhao, J. Wang, F. Wu, T. Wang, Y. Cai, Y. Shi, G. Jiang, J. Hazard. Mater. 173 (2010) 102-109.

[47] B.H. Hameed, Colloids Surf. A 307 (2007) 45-52.

[48] J. Pan, H. Yao, L. Xu, H. Ou, P. Huo, X. Li, Y. Yan, J. Phys. Chem. C 115 (2011) 5440-5449.

[49] G.C. Chen, X.Q. Shan, Y.S. Wang, B. Wen, Z.G. Pei, Y.N. Xie, T. Liu, J.J. Pignatello, Water Res. 43 (2009) 2409-2418.

[50] B.H. Hameed, I.A.W. Tan, A.L. Ahmad, Chem. Eng. J. 144 (2008) 235-244.

[51] H. Niu, Y. Cai, Y. Shi, F. Wei, J. Liu, S. Mou, G. Jiang, Anal. Chim. Acta 594 (2007) 81-92.

[52] E. Tanis, K. Hanna, E. Emmanuel, Colloids Surf. A 327 (2008) 57-63.

[53] J.F. Liu, Z.S. Zhao, G.B. Jiang, Environ. Sci. Technol. 42 (2008) 6949-6954.

[54] D.A. Hinckley, T.F. Bidleman, Environ. Sci. Technol. 23 (1989) 995-1000.

[55] G. Chen, Y. Wang, Z. Pei, Environ. Sci. Pollut. Res. 21 (2013) 2002-2008. 